\title{
SOME ASPECTS OF THE TAXATION OF CAPITAL GAINS
}

\author{
Joseph E. STIGLITZ* \\ Princeton University, Princeton, NJ 08544, USA
}

Received August 1981, revised version received March 1983

The analysis of the effects of capital gains taxation requires a careful modelling both of the details of the tax code and the imperfections in the capital market. Under the standard assumptions concerning perfect capital markets and under the standard idealizations of the tax code, there are several strategies by which rational investors can avoid not only all taxes on their capital income, but also all taxes on their wage income; these strategies leave individuals' consumption and bequests in each state of nature and at each date unchanged from what they would have been in the absence of taxes. Although certain detailed provisions of the tax code may limit the extent to which rational investors can avail themselves of these tax avoidance activities, there are ways, in a perfect capital market, by which the effects of these restrictions can be ameliorated. Accordingly, any analysis of the effects of capital taxation must focus on imperfect capital markets.

If individuals face limitations on the amounts which they can borrow and/or if there are limitations on short sales, then under some circumstances there is a locked-in effect (individuals do not sell securities which they would have sold in the absence of taxation); but under other circumstances individuals are induced to sell securities that they otherwise would have held, in order to take advantage of the asymmetric treatment of short-term losses and long-term gains. A policy of realizing gains as soon as they become eligible for long-term treatment dominates the policy of postponing the realization of capital gains, provided the gains are not too large.

A simple general equilibrium model is constructed within which it is shown that the taxation of capital gains may increase the volatility of asset prices. and lead individuals not to trade when they otherwise would. While the analysis casts doubt on the significance of the welfare losses resulting from these exchange inefficiencies, there are circumstances in which the tax leads to production inefficiencies, e.g. terminating projects at other than the socially optimal date.

Finally, we arguc that the focus of some recent policy debates on the short-run revenuc impact of a decrease in the tax rate on capital gains is misplaced: even when the short-run revenue impact is positive, consumption may increase (thus exacerbating inflationary pressures) and private savings may decrease (thus leading to a lower level of investment in the private sector). Moreover, there is some presumption that the long-run revenue impact is negative.

Our analysis has some important implications for empirical research. In particular, it suggests that the impact of the tax is not adequately summarized by a single number, such as the 'effective tax rate' representing the average ratio of tax payments to capital gains. Moreover, the impact of the tax cannot be assessed by looking only at reported capital gains and losses.

\footnotetext{
*Paper presented to the International Seminar in Public Economics, Paris, June, 1981. Earlier versions of parts of this paper were presented to meetings of the National Bureau of Economic Research Tax Program, in February and July, 1980, and to a seminar at the United States Treasury. I wish to thank the participants in these seminars for their helpful comments. I am particularly indebted to Roger Gordon, Russ Krelove, and Barry Nalebuff for their comments and suggestions.

This research was supported by a contract with the Office of Tax Analysis. The views presented do not necessarily represent the views of the OTA or the Treasury. Financial support from the National Science Foundation is also gratefully acknowledged.
} 


\section{Introduction}

This paper is concerned with the economic effects of capital gains taxation. The tax on capital gains is one of several taxes imposed on the returns to capital. We are concerned with those effects which arise out of the distinguishing features of capital gains taxation - in particular, from the fact that the tax is levied only upon realization of the gains and that the tax imposed is a function of the length of time that the asset has been held and the circumstances upon which the gain is realized.

We began our analysis by asking how would rational investors, facing an idealized form of the U.S. capital tax structure, behave in a perfect capital market. We obtained a set of results, which were perhaps less surprising to those in the investment community than to the evidently poorer academic economists who have previously analyzed the effects of capital gains taxation: with the U.S. tax structure there are a variety of ways by which (with a perfect capital market) a rational investor may avoid not only all taxes on capital, but also taxes on labor income as well. Since taxes may be avoided, taxes are non-distortionary; and since there are a variety of ways by which taxes can be avoided, there is not a single optimal tax reduction investment strategy.

The conclusion that all rational investors can avoid all taxation in a perfect capital market has an easily testable implication: the government should collect no tax revenues from such individuals. The fact that the government does in fact collect a considerable amount of revenue implies that either (a) most individuals are not rational, well-informed investors; (b) capital markets are not perfect; or (c) in the modeling of the tax structure, I have ignored some important details, which limit the extent of applicability of the tax-avoidance schemes. There is undoubtedly some truth in each of these explanations. I argue, however, that while a number of the detailed provisions of the tax code make it more difficult for individuals to engage in these tax-avoidance schemes, and impose a slightly higher order of cleverness on the would-be tax avoider, the level of sophistication required is still far lower than that typically assumed in the modern finance literature. Imperfections in the capital market (limitations on individuals' ability to borrow and to sell securities short) are, I suspect, crucial. ${ }^{1}$ Part II of the paper is thus concerned with the implications for investment strategies of capital gains taxation in an imperfect capital market, in which investors are

\footnotetext{
${ }^{1}$ Even then, if all individuals were rational, well-informed investors, I suspect that we should observe more extensive use of the tax-avoidance activities than we presently observe. And if capital markets were very competitive, with a large number of well-informed brokers providing information concerning tax-avoidance activities to potential investors, we would have expected that the transactions costs associated with many of these tax-avoidance activities would he much lower than they presently are.
} 
limited in the amount which they can borrow (and/or sell short) while part III discusses the welfare implications of capital gains taxation. Part IV discusses briefly the macro-economic consequences of changes in the capital gains tax rate.

\section{PART I}

\section{Tax avoidance in perfect capital markets}

In this scetion we show that with perfect capital markets, and no restrictions on loss offsets or wash sales, there are at least four alternative investment strategies, all of which yield equivalent results: the individual is able to avoid completely paying any taxes, not only on his investment income, but also on his wage income. Consumption of the individual in each state of nature is identical to what it would have been in the absence of taxation. All that the tax system does, is to induce a set of essentially meaningless financial transactions, but these transactions, though intended to avoid taxes, look very much like conventional 'real transactions' (of the kind that one would observe in the absence of taxation).

The four strategies entail:

(1) Postponement of the realization of all long-term gains: the 'locked-in' strategy. We shall refer to this policy as the policy of postponed realization, or the 'locked-in' policy.

(2) Realization of all losses while they are short-term, and of all gains as soon as they become eligible for long-term treatment. We shall refer to this as the policy of immediate realization.

(3) Borrowing to purchase assets which are increasing in value; we shall refer to this as the indebtedness strategy.

(4) Buying and selling highly correlated securities, so that at the end of the year, one is in a position to realize losses to offset income from other sources. In successive years, one engages in similar transactions, to offset both the gains realized from previous transactions of this sort and current wage income. (This is what straddles on the commodity market are designed to do.) We shall refer to this strategy as the loss-roll-over strategy.

Although, with perfect capital markets, these four strategies are equivalent, with imperfect capital markets they are not.

There are three critical properties of perfect capital markets required by our analysis.

(1) There are no restrictions on borrowing; there is a single 'safe' rate of interest (which is the same for borrowing and lending). 
(2) There are no restrictions on short sales; and when an individual sells a security short, he receives the current value of the security as payment. ${ }^{2}$

(3) There are no transactions costs.

In addition, we make use in our analysis of six properties of a tax system: ${ }^{3,4}$

(i) there is no tax on capital gains realized at death;

(ii) there are no restrictions on wash sales;

(iii) there are no restrictions on the ability to use capital losses to offset ordinary income;

(iv) there are no restrictions on interest deductions;

(v) long capital gains are taxed at lower rates than ordinary income; and

(vi) long-term capital gains are taxed at lower rates than short-term.

\subsection{The optimality of postponed realization}

We now establish

Proposition 1. If capital markets are perfect [satisfying conditions (1)-(3)] and the tax system satisfies conditions (i)-(iii), then with rational investors pursuing an extreme 'locked-in' strategy (but hedging the associated risk) the tax system leaves unaffected individuals' consumption and bequests in each state of nature and raises no revenue. ${ }^{5}$

Assume the individual has taxable wage income at time $t$ of $y_{t}$. We show how with only one risky security the individual may manage his portfolio in such a way as to eliminate all tax liabilities. For simplicity, we use discrete time, with the period of analysis corresponding to that for the payment of taxes (a year). We denote with an asterisk values of variables in the no-tax situation, and with a caret the values in the tax avoidance portfolio strategy.

We assume at the beginning of the period he has outstanding debts of $B_{t}$ and outstanding holdings of the risky asset of $A_{t}$. (If there are many risky assets, then $A_{t}$ is to be treated as a vector.) We assume the rate of interest for the period is $r_{t}$, and that all debt is short-term. For simplicity, assume $B_{0}=0$, $A_{0}=0$. Assume the individual would have had an optimal investment

\footnotetext{
${ }^{2}$ Thus, a short sale is just like a loan, except that the amount to be paid back depends on the (random) price of the security (at the time the 'loan' is repaid). This assumption is made to simplify the analysis. It obviously does not provide an accurate description of how short sales occur. The implications of this for the conclusions we reach are discussed below.

${ }^{3}$ For a more extensive discussion of the provisions of the U.S. tax code relating to the taxation of capital gains, see Stiglitz (1981b) or Minarik (1981).

${ }^{4}$ In addition, we ignore the rules relating to the offsetting of long-term gains with short-term losses. But see below.

${ }^{5}$ If capital gains are taxed upon death, it is still optimal to postpone them until then. In that case, our analysis shows that the old adage. 'There are two things in life which cannot be avoided - death and taxes' needs to be modified to read 'You can avoid either taxes or death, but not both.'
} 
strategy in the absence of taxation denoted by $\left\{A_{t}^{*}\left(S_{t}\right), B_{t}^{*}\left(S_{t}\right)\right\}$, where $S_{t}$ denotes the 'state' of nature at time $t$ (a complete description of the history of the economy up to that date). The individual's consumption profile is thus described by

$$
\begin{aligned}
C_{t}\left(S_{t}\right)= & y_{t}-r_{t-1}\left(S_{t-1}\right) B_{t-1}^{*}\left(S_{t-1}\right)+\left\{B_{t}^{*}\left(S_{t}\right)-B_{t-1}^{*}\left(S_{t-1}\right)\right\} \\
& -p_{t}\left(S_{t}\right)\left[A_{t}^{*}\left(S_{t}\right)-A_{t-1}^{*}\left(S_{t-1}\right)\right]
\end{aligned}
$$

where $p_{z}$ is the price of the asset in the $t$ th period. For simplicity, we have assumed risky assets pay no dividends. ${ }^{6}$ (The modifications required if firms pay dividends are straightforward.)

Assume that with probability one: ${ }^{7}$

$$
p_{t}\left(S_{t}\right) \neq p_{t-1}\left(S_{t-1}\right) \text { for all }\left\{S_{t}, S_{t-1}\right\}
$$

and, for simplicity, that

$$
\min \left|p_{t}\left(S_{t}\right)-p_{t-1}\left(S_{t-1}\right)\right|=l_{t}\left(S_{t-1}\right)>0 .
$$

Assume in the first period the individual sets

$$
\hat{A}_{0}\left(S_{0}\right)=A_{0}^{*}\left(S_{0}\right)+y_{1} / l_{1},
$$

but simultaneously sells short $y_{1} / l_{1}$ units of the asset, so the net position remains $A_{0}^{*}$. Then, at the end of the period, the individual will have made a loss either on the asset or on the short sales. If $p_{1}>p_{0}$, he closes out the short sale for a net loss of

$$
\left(p_{1}-p_{0}\right) \frac{y_{1}}{l_{1}} \geqq y_{1},
$$

so he will have no tax liability. He then again sells short $y_{1} / l_{1}$ units of the asset, so he again carries forward a net position of $A_{0}^{*}$.

He then purchases an additional amount

$$
A_{1}^{*}-A_{0}^{*}+\frac{y_{2}}{l_{2}}
$$

${ }^{\circ}$ As I pointed out in 1973 , it is difficult to explain why rational firms pay dividends. The subsequent literature trying to explain the 'dividend paradox' has left me unconvinced, particularly with respect to the tax-avoidance activities of closely held companies. For a further discussion, see Stiglitz (1982b).

${ }^{7}$ In continuous time, all we would require is that within the year interval, the probability that the movement of price from the original price exceeded $1_{t}$ in absolute value was unity; this would be satisfied with any stochastic process described by a diffusion equation with positive variance. 
selling short an additional amount $y_{2} / l_{2} \cdot{ }^{8}$ Following the same procedure as the previous period, he then more than eliminates all the tax liabilities he has accrued in that period.

The process continues until, at death, all shares are realized. Since all gains are assumed to escape taxation upon dcath, this proccdure has enabled the individual to avoid completely all income and capital taxation, and to leave his consumption and bequests identical to what they would have been (in every state of nature) in the absence of taxation. (I'he procedure we have outlined is, of course, not the only procedure that would have worked; in particular, it is not the procedure which minimizes the number of transactions, since no account is taken of the previous positions taken, and the prices at which the securities were purchased at earlier dates.)

\subsection{An alternative procedure for avoiding taxation: The optimality of immediate realization}

In this section we show that there is an equally effective way of avoiding taxation when there is a differential tax rate on long- and short-term gains and losses. We assume the capital market is perfect (in the sense defined above); but now, we assume the tax system has the additional critical property ${ }^{9}$ that long-term gains are taxed at $z$ times the rate on short-term gains.

Throughout the analysis we assume a 'flexible' time period: the individual can realize a gain or loss just before or after the end of the period, thus recording either a short-term loss or a long-term gain.

We employ exactly the same model and notation as in the previous subsection. We assume that the individual takes precisely the same investment decisions as in the previous model at the end of the zeroth period. At the end of the first period, if there is a decline in price, the individual realizes the loss, just as he did earlier. But now he sells his entire 'long' position. This implies that during the first period the individual will have no tax liability, and will have a tax loss carry over of

$$
\tau\left[\left(p_{0}-p_{1}\right)\left[A_{0}^{*}+\frac{y_{1}}{l_{1}}\right]-y_{1}\right]
$$

(where $\tau$ is the tax rate).

\footnotetext{
${ }^{8}$ If $A_{1}^{*}<A_{0}^{*}$, he will need to purchase an additional amount of $y_{2} / l_{2}$ and sell short an additional amount of $y_{2} / l_{2}+A_{0}^{*}-A_{1}^{*}$ to attain his desired position.

${ }^{9} \mathrm{We}$ also assume that long-term gains are not used to offset short-term losses on a one-to-one basis. See below.
} 
At the beginning of the next period he closes out his short position, incurring a long-term tax liability of

$$
\left(p_{a}-p_{1}\right) z \tau \frac{y_{1}}{l_{1}} .
$$

His net tax liability at that juncture is

$$
\tau L_{1} \equiv \tau\left[\left(p_{0}-p_{1}\right)\left[(z-1) y_{1} / l_{1}-A_{0}^{*}\right]+y_{1}\right] .
$$

If $z$ is small, $L_{1}$ will frequently be negative. ${ }^{10}$

Similarly, if there is a rise in price he closes out his short position just short of a year, eliminating his tax liability and establishing a loss carry forward of

$$
\tau\left[\left(p_{1}-p_{0}\right) \frac{y_{1}}{l_{1}}-y_{1}\right] .
$$

At the beginning of the next period, he closes out his long position, incurring a long-term tax liability of

$$
z \tau\left(p_{1}-p_{0}\right)\left[A_{0}^{*}+\frac{y_{1}}{l_{1}}\right] .
$$

Now, his net liability on the capital account is

$$
L_{1}=\left[\left(p_{1}-p_{0}\right)\left((z-1) \frac{y_{1}}{l_{1}}+z A_{0}^{*}\right)+y_{1}\right] .
$$

Again, at the beginning of the period the individual re-establishes his position, now setting

$$
\hat{A}_{1}=A_{1}^{*}+\frac{y_{2}+L_{1}}{l_{2}}
$$

and selling short $\left(y_{2}+L_{1}\right) / l_{2}$ units of the risky asset. This ensures that at the end of the period he will have sufficient losses not only to eliminate any outstanding tax liability on capital account, but also to eliminate any tax liability on his wage income.

\footnotetext{
${ }^{10} \mathrm{We}$ assume long-term gains and losses are taxed at the rate $2 \tau$ and the resulting tax is simply added to the tax liability on short-term gains (losses).
} 
The procedure continues, until the individual dies, in which case any outstanding liabilities are escaped. Note that again, in this procedure, consumption in each state is the same as it was without taxation, and the individual's net position in each state was identical to what it would have been without taxation.

We have thus established:

Proposition 2. With perfect capital markets [satisfying conditions (1)-(3)] and a tax system satisfying conditions (i)-(iii) and (vi), then, with rational investors, realizing all losses as soon as they occur, and all gains as soon as they become eligible for long term treatment, accompanied by the appropriate hedging strategy, consumption and bequests of the individual in every state of nature will be the same as it would be without taxation and the tax system raises no revenues.

\subsection{A third procedure for the avoidance of taxation: The optimality of indebtedness}

There is another procedure for the avoidance of taxation, if there is an asset yielding a sure capital gain at the rate $r^{*}$, and if interest is deductible. The individual simply borrows

$$
y_{t} / r_{t-1}
$$

at date $t-1$, so that his interest for the $t$ th period is

$$
r_{t-1}\left(\frac{y_{t}}{r_{t-1}}\right)=y_{t}
$$

He will thus have no tax liability. With the proceeds, he purchases the asset yielding the sure capital gain, postponing the realization of the capital gain until death, at which point he repays the debt. ${ }^{11}$ Note that if the individual uses the asset as a collateral for the loan, the lender incurs no risk in the transaction.

This, again, is only one of several possible ways to avoid taxation. If there is favorable treatment of long-term gains, the individual could just as well have avoided taxes by realizing his capital gain as soon as it becomes eligible

\footnotetext{
${ }^{11}$ If along the no-tax optimal investment strategy, he would, in some state, have reduced his holdings of the risky asset $\left(A_{t+1}^{*}<A_{t}^{*}\right)$, and if there would, as a result, be a capital gains tax liability, the individual must that period borrow an additional amount to offset this tax liability. Alternatively, instead of selling some of the risky asset, he sells short an equivalent amount. If the sale results in a capital loss, the individual need borrow less.
} 
for long-term treatment. Then he will have a tax liability on the gain of (assume $r_{t}=r^{*}$, all $t$ )

$$
z \cdot r^{*} \frac{y_{1}}{r^{*}}=z y_{1}
$$

He then borrows enough to offset this as well as his wage income next period. At the $t$ th period, the individual's indebtedness will be

$$
\frac{1}{r^{*}} \sum_{i=0}^{t-1} y_{t-i} z^{i}
$$

Similar results obtain if there is some asset whose minimal return is positive. Assume $p_{t} / p_{t-1}>\gamma$ and assume the individual sells an option to buy the security at price $\gamma p_{t-1}$, at a price $q_{t-1}$. With the proceeds of this and a loan of $\alpha$ dollars, he purchases shares of the security. His net position at the end of the period is

$$
\frac{\tilde{p}_{t}}{p_{t-1}}\left(\alpha+q_{t-1}\right)-\left\{\tilde{p}_{t}-\gamma p_{t-1}\right\}-(1+r) \alpha,
$$

where $\tilde{p}_{t}$ is the realization of $p_{t}$. This is a pure arbitrage operation, provided

$$
\alpha+q_{\imath-1}=p_{\imath-1}
$$

and

$$
\propto(1+r)=\gamma p_{t-1}
$$

Then, if the option can be held long enough to be eligible for long-term treatment, the individual can use the deductibility of interest to offset all of his tax liabilities.

We summarize the results of this subsection in:

Proposition 3a. If there is a perfect capital market [conditions (1)-(3) are satisfied], and the tax system satisfies assumptions (i)-(iv) and, in addition, there exists an asset yielding a perfectly safe capital gain, then there exists an optimal investment strategy with individuals borrowing to invest in the safe asset, and postponing the realization of capital gains until death. With this investment strategy, consumption and bequests are identical to what they would be in every state of nature in the absence of taxation, and no revenue is collected by the tax. ${ }^{12}$

\footnotetext{
${ }^{12}$ Again, as in the previous two strategies, there are several ways by which this basic policy may be implemented. 
Proposition 3b. Under the conditions of proposition $3 a$, if in addition, there is favorable treatment of long-term capital gains [tax condition (v)], then there exists an optimal investment strategy with individuals borrowing to invest in the safe asset, and realizing capital gains on the safe asset as soon as they become eligible for long-term treatment, which leaves consumption and bequests unchanged and the tax raises no revenue.

Proposition 3c. Assume the conditions of proposition 3a, except now, assume (a) there exists no safe asset, but there exists a risky asset with a minimal positive return; and (b) there exists an options market for the asset (with zero transactions costs), with a maturity of one year (so it is eligible for long term treatment if held to maturity). Then, there exists an optimal investment strategy with individuals borrowing, selling options, and buying the security with minimal positive return. This investment strategy leaves consumption and bequests unchanged and the tax raises no revenue.

\subsection{The optimality of roll-over strategies}

The fourth strategy for avoiding taxation is similar to the second, with one major difference. It does not require that there be any advantageous treatment of long-term capital gains. All that is required is that gains and losses be taxed only upon realization (what we identified as one of the distinctive properties of capital gains taxation).

The individual buys and sells short a sufficient amount of the risky asset, so that, with probability one, at the end of the year, he has a loss on one side of the transaction large enough to offset his other sources of income, i.e. he sets

$$
\widehat{A}_{0}\left(S_{0}\right)=A_{0}^{*}\left(S_{0}\right)+y_{1} / l_{1} \text {. }
$$

At the end of the year, he realizes that part of the transaction on which he has made a loss, e.g. if $p_{1}<p_{0}$, he sells the security, recording a loss of

$$
\left(p_{0}-p_{1}\right) y_{1} / l_{1} \geqq y_{1} \text {. }
$$

He thus carries forward into the next tax year a loss of

$$
\left(p_{0}-p_{1}-l_{1}\right) y_{1} / l_{1}
$$

At the beginning of the next period he closes out his position, so that at the beginning of the year he has an accrued tax liability of $\tau y_{1}$ (where $\tau$ is the tax rate). The next year he buys and sells short enough of the security to enable him to offset both his income and his accrued tax liability; he 
purchases

$$
\hat{A}_{1}\left(S_{1}\right)=A_{1}^{*}\left(S_{1}\right)+\left(y_{1}+y_{2}\right) / l_{2}
$$

of the asset, while selling short

$$
\left(y_{1}+y_{2}\right) / l_{2} \text {, }
$$

so his net speculative position is unchanged. The process repeats itself, so that in the $t$ th year, he sets

$$
A_{t}\left(S_{t}\right)=A_{t}^{*}\left(S_{t}\right)+\sum_{i=1}^{t+1} y_{i} / l_{t+1}
$$

and sells short an amount

$$
\sum_{i=1}^{t+1} y_{i} / l_{t+1}
$$

of the asset.

This process thus enables him to postpone all of his tax liabilities until death. We thus have established.

Proposition 4. With a perfect capital market [satisfying properties (1)-(3)] and a tax system satisfying properties (i)-(iii), then the roll-over strategy is optimal. Individuals are able by using this strategy to avoid all taxation, and their consumption and bequests in each state of nature is unaffected by the tax.

\section{Avoiding tax restrictions}

In the previous analysis we made two important, and unrealistic, assumptions concerning the tax code: we assumed that there were no restrictions on wash sales and full loss offsets. In this section ve show how these restrictions may be avoided.

\subsection{Perfect capital markets with restrictions on wash sales}

In this section we show that the restrictions on wash sales need not be binding. It is widely believed that by buying a sufficiently large number of randomly chosen securities, one can obtain a portfolio (it is often argued that only 25 are in fact required) which is virtually perfectly correlated with the market as a whole. This is an implication of both the capital asset pricing model and the arbitrage model. If this assumption is not true, then the 
capital markets cannot be perfectly competitive [and the market equilibrium will not, in general, be Pareto optimal; see Stiglitz (1981a)]. We shall refer to a capital market which satisfies, in addition to conditions (1)-(3), condition (4) below, a perfect competitive capital market:

(4) There arc at least two assets (or portfolios of assets) with perfectly correlated returns.

We assume that the restrictions on wash sales take the form that the individual cannot simultaneously (or within a short time span - here taken to be the next period) purchase and sell the same asset. We focus our discussion on proposition 2, where the individual does this to take advantage of the favorable treatment of long-term gains. Now instead of selling short $y_{1} / l_{1}$ units of asset ' $\alpha$ ', he sells short $y_{1} / l_{1}$ units of asset ' $\beta$ '. If $p_{1}>p_{0}$, at the end of the period he realizes the loss on his ' $\beta$ ' position, and at the beginning of the next period (as soon as the asset becomes eligible for long-term treatment) he sells his $A_{0}^{*}+y_{1} / l_{1}$ units of ' $\alpha$ '. He then goes 'long' in $\beta$ in the amount $A_{1}^{*}+\left[\left(y_{2}+L_{1}\right) / l_{2}\right]$, and 'short' in $\alpha$, in the amount $\left(y_{2}+L_{1}\right) / l_{2}$. The procedure continues as before; each period the individual 'reverses' his position.

More generally, we can establish:

Proposition 5. With a perfect capital market [satisfying conditions (1)-(4)] tax restrictions on wash sales need never be binding; any consumption-bequest plan which could be achieved in the absence of the provisions relating to the tax treatment of wash sales can be achieved with the wash sale provisions; in particular, gains are realized as soon as they become eligible for long-term treatment.

There exist portfolio policies implementing the tax-avoidance strategies described by propositions $1-4$ in which the provisions relating to the tax treatment of wash sales are irrelevant. ${ }^{13}$

\subsection{Restrictions on loss offsets}

In the previous analysis we allowed the individual to use capital losses to offset ordinary income. In fact, of course, only $\$ 3,000$ of capital losses can be used within any year to offset ordinary income. If this constraint were an important one, we would observe most individuals operating against it.

\footnotetext{
${ }^{13}$ It should be noted that recent legislation attempting to restrict straddles in the commodity markets has included a set of provisions which, if enforced, might restrict the kinds of transactions just described. On the other hand, the enforcement would require a complicated analysis of the statistical properties of the securities purchased by each individual; if enforced, its effects on the securities markel could be profound.
} 
There are, however, a variety of ways by which the impact of this constraint may be reduced.

The simplest method entails taking advantage of the deductibility of interest payments, by borrowing and purchasing a safe asset which yields its returns in the form of capital gains.

Even if there does not exist a perfectly safe asset, the individual can obtain equivalent results if there exists a security with a minimal positive capital gain, by selling an option on the security, as described in section 2.3. Alternatively, the individual can 'lend' money to the stock market through the options market, attaining a safe return in the form of capital gains. To do this, assume the current price of the asset is $p_{t}$. The individual buys one unit of the security, buys a put for $q_{p}$ with a striking price, $p_{s}$, exceeding the current price (so his return next period is $\max \left[0, p_{s}-p_{t+1}\right]$ and sells an option for $q_{0}$ with the same striking price, so his return next period is $\min \left[0, p_{s}-p_{t+1}\right]$. Thus, his net income next period is just $p_{s}$, and in equilibrium

$$
p_{s}=\left(1+r^{*}\right)\left[p_{t}+q_{p}-q_{0}\right]
$$

where $r^{*}$ is the safe rate of interest. Since his return is perfectly safe, it must be equal to the safe rate of interest.

There are, however, alternative methods which are commonly employed. An individual can purchase an asset with borrowed funds for which the depreciation allowance exceeds the true economic depreciation. If the depreciation allowances plus interest on the loan exceed the flow of quasirents from the asset, then there will be an ordinary income loss, with a subsequent capital gain.

An individual can sell short a security shortly before a dividend is due. Following the payment of the dividend, the price of the security will decline, and he will experience a capital gain; this is offset by the dividend payment which he must make, but the latter is deductible against ordinary income [see Allen (1982)].

The 1981 tax law imposed restrictions on several of the devices for converting capital losses into ordinary income losses, and thereby evading the restrictions on loss offsets. These include taking advantage of the provisions related to the tax treatment of Treasury Bills, Cash and Carry Transactions, and the tax treatment of traders.

\subsection{Implications of wash sale and loss offset provisions}

The restrictions on wash sales and loss offsets are particularly important for the investment strategy which we have called that of immediate realization'. But the restriction on wash sales also has implications for the 
first strategy, that which we have referred to as the 'postponement strategy'. For if individuals are to postpone their tax liability, without at the same time increasing their position in the security beyond the desired level, then the individual must hedge his position (e.g. by selling the security short). But if he does this within a ycar of purchase, although he may be able to postpone the tax, the transaction will not be eligible for long-term treatment.

If the restrictions imply that the individual cannot use the special treatment of capital gains to reduce the tax liability on ordinary income (by more than the $\$ 3,000$ loss offset plus the interest on the amount which the individual can borrow), he can still use these provisions to eliminate any tax liability on his capital income.

\subsection{Further comments on the implications of special provisions}

There are several other special provisions of the tax code relating to the treatment of capital income which impinge on the individual's ability to implement the tax avoidance strategies described earlier.

We referred, for instance, to the provisions concerning the treatment of short-term capital losses in the presence of long-term capital gains. The methods which we described above of converting ordinary income into shortterm capital gains, to avoid the limitations on the deductibility of losses, may be used to vitiate the effects of these provisions as well.

The provisions restricting the amount of interest which can be deducted are relevant for the indebtedness strategy described in proposition 3 . Empirically, this restriction does not seem to be binding [see Feenberg (1981)] which suggests that there are easy ways by which the restriction can be avoided, e.g. by taking advantage of the peculiarities in the definition of those kinds of investment income which can be used to increase the amount of interest which can be deducted and/or that the present tax code provides alternative and equally effective ways by which taxes can be avoided (as our analysis has already suggested).

Some of the special provisions of the tax code make tax avoidance easier. For instance, if a bond were sold below par, the increase in the value of the bond between the purchase date and the maturity date is not treated as a capital gain, but as interest income (closing what would be an obvious tax avoidance scheme.) Prior to 1982 for a $T$ year bond, $1 / T$ of the capital gain was imputed as income to the owner of the bond and $1 / T$ was deductible as an interest expense by the seller. For simplicity, assume the interest rate is fixed. In the absence of taxation, an individual or firm which sold a $T$ period zero coupon bond, and used the proceeds to buy a $T$ period coupon bond, investing the interest payments at the same safe rate of interest, was able at the end of $T$ periods with the proceeds to pay off the holders of the zero coupon bonds. He would be indifferent to undertaking the transaction. With 
taxation, however, there is every year a tax reduction in the amount of ${ }^{14}$

$$
\frac{\tau}{T}\left\{1-\mathrm{e}^{-r T}-r T \mathrm{e}^{-r T}\right\}
$$

which he can use to offset either ordinary or capital income. ${ }^{15}$

Here, as elsewhere, we have ignored the general equilibrium aspects of tax avoidance; the arithmetic imputation scheme increases the tax liability of the individual purchasing the bond. If there was no tax-exempt institutions or individuals facing a zero marginal tax rate, this should be reflected in the price which a buyer is willing to pay for such a bond. Provided, however, there are tax-exempt institutions, they should be willing to buy the zero coupon bonds and sell the coupon bonds; in equilibrium a one dollar $T$ period zero coupon bond should sell for $\mathrm{e}^{-\boldsymbol{r} T}$.

\section{PART II}

\section{Imperfect capital markets}

The analysis of part I made the kinds of 'perfect market' assumptions conventional in the finance literature, and the simplifications in the tax code that we employed in our analysis were again of the kind that are frequently found both in textbook expositions and in analytical discussions in the public finance literature. Yet the results which emerge were clearly unrealistic: individuals do pay taxes, and the taxes surely do affect both the real investment decisions and consumption decisions of individuals.

Thus, an analysis of the impact of the capital gains tax must focus on the imperfections of the capital market and on at least some of the detailed provisions of the tax code.

In the previous section we showed how those provisions of the tax code which, it is commonly argued, restrict individuals' abilities to avoid taxes in the way that we described in propositions 1-4 would not, in a perfectly competitive capital market, be binding. More generally, it is our contention that even if the detailed provisions of the tax code put some limits on the extent to which individuals can avoid taxes, if investors were rational and if capital markets were perfect, there would be much more tax avoidance than

\footnotetext{
${ }^{14} \mathrm{~A}$ zero coupon bond promising to pay $\$ 1$ in $T$ periods sells for $\mathrm{e}^{-r T}$ today; the capital gain is $1-\mathrm{e}^{-r T}$ and hence the inputed interest is $\left(1-\mathrm{e}^{-r T}\right) / T$.

${ }^{15}$ Similar avoidance schemes can be implemented with uncertain interest rates, but they require more complicated portfolio strategies for the individual to be perfectly hedged. Though the substitution of exponential for arithmetic imputation schemes eliminates the use of this taxavoidance scheme when interest rates are not variable, when they are, a more complicated taxa voidance arbitrage scheme can be devised.
} 
is presently observed. Thus, the remainder of this paper is devoted to the analysis of the consequences of capital gains taxation with imperfect capital markets.

Not surprisingly, the consequences depend critically on precisely what constraints are binding, e.g. whether there is a borrowing constraint or a short sale constraint. Although the four policies we outlined in the previous section are all equivalent in a perfect market - they all succeed in eliminating all tax liabilities - they involve quite different transactions (and transactions costs). For instance, the policy of postponed realization (the locked-in strategy) may require large amounts of short sales, and, under present institutional arrangements (where a short sale is not just the negative of a purchase) this may entail significant amounts of borrowing. Similarly, the roll-over strategy requires increasing amounts of short sales over time. Borrowing constraints are obviously critical for the third strategy. In contrast, borrowing is not so critical for the policy of immediate realization. Limitations on loss offsets are, however, critical for this strategy, as well as for the policy of postponed realization and the roll-over strategy. In the next section we detail the effects of capital gains taxation under a variety of imperfect capital market conditions.

\section{The basic intertemporal trade-offs in the timing of capital gains}

The central feature of the capital gains tax upon which we focus is that investors can time their realization of gains and losses, and by doing so affect their tax liabilities. We shall show that paying careful attention to this aspect of investment strategy may, in fact, yield far higher after-tax returns than paying a corresponding amount of attention to the choice of alternative assets (particularly if one believes in the random walk hypothesis).

When an individual decides to realize a gain today rather than at some later date, he affects not only his tax liability today, but also his tax liability at that later date. Thus, the impact of the capital gains tax can only be assessed within an intertemporal model. There are three basic effects, which we refer to as the rate effect, the PDV effect, and the risk effect.

\subsection{The rate effect}

The timing of the realization of a gain or loss affects the tax rate which is imposed: ${ }^{16}$

\footnotetext{
${ }^{16}$ This list is not meant to be exhaustive; for instance, an individual who is planning to give a gift next year to a charitable foundation might be better off not realizing a capital gain this year. but rather giving the security directly to the foundation next year.
} 
(i) By postponing realization, a short-term gain may be converted into a long-term gain; or conversely.

(ii) By realizing a loss early, it may be treated as short-term, rather than long-term.

(iii) By postponing rcalization until death, the capital gains tax may be avoided entirely.

(iv) Consider an asset purchased at $t_{0}$. Assume that the individual realizes a loss at date $t_{1}$, and reinvests the proceeds in a similar asset. Assume at $t_{2}$ an event occurs which necessitates that individual selling his asset. If $1+t_{0}<t_{2}<1+t_{1}$, then this change in value between $t_{1}$ and $t_{2}$ is treated as short-term, while if the individual had not realized his loss at $t_{1}$, it would have been treated as long-term. If there is a large gain between $t_{1}$ and $t_{2}$, the individual is worse off; if there is a loss, he is better off. This argument assumes an imperfect capital market; as we argue below, if the individual could borrow or sell short an essentially equivalent security, then he would not need to sell his asset, even if a contingency arose which required the expenditure of a significant fraction of his net worth. ${ }^{17}$

(v) The realization of a large capital gain in one particular year may result (because of the progressivity of the tax structure and the imperfect provisions for averaging) in the individual facing a heavier tax liability than if the asset were sold gradually over a number of years. At the same time, the ability to time the realization of capital gains and losses may enhance the effective degree of averaging associated with the income tax structure. ${ }^{18}$

Equally important, if the individual has a realized (short-term or longterm) loss exceeding the limitations on loss offsets, then the effective current marginal tax rate on any realized gains is zero.

\subsection{The PDV effect}

By postponing the realization of a gain, the present discounted value of the tax liability on the gain is reduced (if the rate of interest is positive); conversely, by realizing a loss as soon as it occurs, the present discounted value of the implicit tax reduction is increased.

Conversely, if there was no inflation, but the real rate of interest was negative, the individual would lower his tax liability by realizing gains as soon as they occur and postponing tax losses. Effectively, the government borrows money paying a zero rate of interest, while all other borrowers pay negative interest rates, and hence the individual prefers to lend to the government by realizing only gains and postponing all losses.

\footnotetext{
${ }^{17}$ Restrictions on wash sales may still impede the individual's ability to realize the gain at favorable capital gains rates.

${ }^{18}$ Differences in tax rates are important in understanding the impact of capital taxes within a general equilibrium context. See, for example, Atkinson and Stiglitz (1980).

J.P.E.-- G
} 


\subsection{Risk effects}

The realization of a gain this year may make it possible for the individual to realize a loss next period which the individual otherwise would not be able to realize. Of course, if the individual were sure that the asset were going to decrease in value, then he would clearly not keep the asset (in the absence of taxation). But if there is some chance that it will decrease in value, and if there is differential treatment of long-term gains and short-term losses, it may pay the individual to realize the gain today. Assume, for instance, that the individual purchased an asset at a price $p_{0}$, and its present price is $p_{1}$. Assume there is some probability that the price will fall back to $p_{0}$ and some probability that it will rise to $p_{2}$. By realizing the gain today, the individual increases his tax liability by $z \tau\left(p_{1}-p_{0}\right)$, where $z \tau$ is the tax on long-term capital gains. If the price falls to $p_{0}$ his tax liability next period will be reduced $\tau\left(p_{1}-p_{0}\right)$, where $\tau$ is the tax on short-term capital gains. If the price rises, assume he sells the asset at some date $\hat{t}$ periods later, the same as he had planned to do originally. We assume this date is sufficiently far in the future that any gain will be eligible for treatment as long-term. His tax liability at this date is increased by $z \tau\left(p_{1} p_{0}\right)$. The change in the expected present discounted value of his tax liability is

$$
\tau\left(p_{1}-p_{0}\right)\left[z-\left(\frac{\pi}{1+r}+\frac{(1-\pi) z}{(1+r)^{t}}\right)\right]
$$

where $\pi$ is the probability of the price falling, and $r$ is the interest rate. Note that if $r=0$, but $z<1$, the policy of immediate realization has a lower PDV, while if $z=1$ and $r>0$, the policy of postponed realization has a lower PDV.

The individual is effectively giving money to the government at date $t-1$ for the 'right' to obtain money from it at date $t$, if the price of the security goes down.

This way of putting the problem makes it clear that the right to realize a short-term loss and receive an offset against other income is like a put: the value of the option increases the lower the price of the security and is greater the greater is ?. Moreover, the put 'expires' in a year. The price paid for the option is the increase in tax liability, at date $t-1$, from realizing the capital gain. It is lower the lower is $z$ and higher the higher is the price relative to the original purchase price. Finally, since the loss will occur in the future, while he has to pay for the right to take the loss today, the value of this option depends on the rate of discount.

This risk effect will play an important role in our subsequent analysis. If individuals are risk averse, this effect, arising out of the stochastic nature of assets, is even greater. 


\subsection{Risk aversion}

The PDV effect, which we discussed above, reflects the fact that a dollar today is not equivalent to a dollar tomorrow. Present dollars are worth more than future dollars. In addition, income in some events (states of nature) may be worth more than income in other events (states of nature). If there were perfect insurance markets, then the individual would have equated the marginal utility of income in all states. ${ }^{19}$ But there are not perfect insurance markets, and hence the marginal utility of income in some states may exceed that in others. Thus, let us return to our example of an individual who has an asset which has increased in value from $p_{0}$ to $p_{1}$. There is some chance that next year will be a recession, in which case his wage will be lower (but not sufficiently lower to reduce his marginal tax bracket). The individual would like to insure against this event, but cannot obtain insurance in the market. He may, however, be able to obtain some insurance through the tax system. Assume that if there is a recession the price will fall back to $p_{0}$. We noted above that by realizing the gain today, he increases his current tax liability by $z \tau\left(p_{1}-p_{0}\right)$. But then, if the recession occurs, he will be able to reduce his tax liability by $\tau\left(p_{1}-p_{0}\right)$. If the marginal utility of income in the recession is sufficiently high, he will be willing to purchase this 'insurance', even though the expected present discounted value of his tax liabilities is thereby increased. ${ }^{20.21}$

The mathematical models that we present in the subsequent sections help to clarify the nature of the important intertemporal trade-offs that we have identified in this section.

\section{Optimal investment strategy for a short-term investor}

In this section we analyze the optimal investment strategy for a short-term investor. We assume that he knows that at the end of, say, two periods, he will wish to cash in his investments. His objective then is simply to maximize the expected value of his terminal wealth at the end of two periods. His

\footnotetext{
${ }^{19}$ More accurately, the individual would have purchased complete insurance for all 'individualistic' events, i.e. all events which the market can diversify out of.

${ }^{20}$ This effect may be particularly pronounced if there are both incomplete risk markets and imperfect capital markets. If individuals could easily borrow (never faced credit constraints), then the individual could 'smooth' the loss of income which occurs next period over an extended period of time. Thus, the difference in his marginal utility of income might be relatively small. However, if there are borrowing constraints, the reduction in income next period may result in a marked decrease in consumption and a corresponding increase in the marginal utility of (current) income.

${ }^{21}$ The 'price' the individual pays for this 'insurance' depends on the tax structure. If there is no favorable treatment of long-term gains, then the price (in terms of the reduction in the expected present discounted value of his consumption) is positive, while if there is favorable treatment of long-term gains, this strategy may actually increase the expected present discounted value of his consumption, as we saw above.
} 
initial wealth is $W_{0}$. The probability distribution of the percentage increase in the price of the asset is given by $F\left(p_{t} / p_{t-1}\right)$ and is the same for all $t$. We choose our units so that initially the individual has one unit of wealth, and purchases one unit of the asset, with $p_{0}=1$. At the end of the first period the asset is worth $p_{1}$. The individual can either sell his asset, repurchasing an identical asset, paying out or receiving from the government a capital gains tax (short- or long-term, as the individual times his sales on the 365 th or 366 th day); or he can retain his asset. The second period, the individual will sell his asset. If he retained his asset in the preceding period, it will be subjected to long-term taxation; otherwise, it will be subjected to long-term or short-term taxation at the individual's discretion. Straightforward calculations establish that

Proposition 6 . There exists a critical value of $p_{1}>1$ denoted by $\hat{p}$, such that for $p_{1}<\hat{p}$ the individual sells his asset while for $p_{1}>\hat{p}$ the individual retains his asset.

Further, it can be shown that

$$
\hat{p}=\frac{z[\bar{\gamma}(1-\tau)+\tau(1-z) g(1-F(1))]}{(1-z \tau)(\bar{\gamma}-(1-z) g(1-F(1)))}
$$

where

$F(1)=$ fraction of time that a loss occurs,

$$
g \equiv \int_{1}^{\infty}(p-1) \mathrm{d} F /(1-F(1))=\begin{aligned}
& \text { percentage mean value of a gain, } \\
& \text { conditional on a gain occurring. }
\end{aligned}
$$

and

$\bar{\gamma}$ is the average rate of return on the asset.

From this we can easily calculate the fraction of the time that individuals do not turn over their securities at the end of the year, $F(\hat{p})$. It is clear that $\hat{p}$ depends on the following.

(1) If $z=1$, i.e. full taxation of capital gains, then $\hat{p}=1$, the individual realizes all losses, but postpones all gains. As $z \rightarrow 0, \hat{p} \rightarrow \infty$.

(2) If $\bar{\gamma}=0$, the individual realizes all losses as short-term, and all gains as soon as they become eligible for long-term treatment. The reason for this is that, in this model, funds are reinvested in the same asset. Hence, the effective discount rate is zero and there is no advantage to postponing the realization of capital gains.

(3) The larger the mean return, the smaller $\hat{p}$, while the larger the expected value of the loss, conditional on a loss occurring, the larger $\hat{p}$. Moreover, the 
smaller $z$, the larger the advantages to be had from the asymmetric treatment of gains and losses, and therefore the larger $\hat{p}$.

\section{Long-term investors}

Similar conditions can be used to show that long-term investors too may find it optimal to realize their capital gains as soon as they become eligible for long-term treatment. The analysis is, however, considerably more complicated. We focus on the case where the stochastic process describing the asset's price is stationary. ${ }^{22}$ Assume we buy an asset at $p=1$, and let the minimum holding period for long-term treatment be one period. (These are just normalizations.) There is a constant probability $\lambda \geqq 0$ that the individual will have to realize the asset at date $t .^{23}$ Then the optimal policy may be simply described as follows.

There is a critical price $\hat{p}(t)$ such that if $p(t)<\hat{p}(t)$ the loss should be realized. The costs of realization at date $t$ are (i) there is a chance that in the interval $(t, 1+t)$ there will be a 'forced' realization, which will be treated as short-term, which, otherwise, would be treated as long-term; and (ii) if $\hat{p}<1$ to take advantage of a tax loss at a subsequent date the price must fall still further.

We suggested above that one could think of the right to obtain a tax loss as a put, with a fixed termination date of a year. But unlike conventional puts, whenever the put is exercised, it is replaced by a new put, somewhat less attractive (if $\hat{p}<1$ ) in its striking price than the original put but with a longer maturity. The benefit (if $\hat{p}<1$ ), is the tax rebate.

Consider first the case where the probability of a forced realization is zero. Clearly, $\hat{p} \geqq 1$ for $0 \leqq t \leqq 1$. For if the price ever returns to its original level, the individual can replace the 'old' put with a new put, at no cost. The return from doing so increases with $t$. The old put and the new puts are identical, at $t=0$, and hence there is no benefit to replacing one with the other. Hence, $\hat{p}(0)=1$.

This result may be seen in a slightly different way. Assume, at $t=1, \hat{p}(t)=1$, i.e. the investor always retains assets on which he has earned a long-term capital gain. Assume the individual will not sell the asset (for consumption purposes) for an extended period of time (more than a year). Then, there is a finite probability within a year if $p$ is near unity that the price will become less than unity (as $p$ approaches unity, this probability increases.) If $p$ does become less than unity, there is a finite gain to being in a position to realize the loss as a short-term loss. Since as $p \rightarrow 1$ the cost of being in this position goes to zero, it is clear that $\hat{p}$ must exceed one.

With forced realizations, we need to ask: Would an individual be willing to pay a positive price for a contract which gave the individual an additional

\footnotetext{
${ }^{22}$ The assumption of stationarity is important, as the analysis of Stiglitz (1981b) shows.
}

${ }^{23}$ Again, we are making use of the assumption of a binding borrowing constraint. 
amount of $\tau\left(p_{1}-p_{t}\right)$ if $p_{t}<p_{1}$, but where he would have to pay an additional amount of $\tau\left(p_{t}-p_{1}\right)(1-z)$ if $p_{t}>p_{1}$, if he sells the asset within a year, knowing that there is some probability that he will involuntarily have to sell the asset during that interval? From what we said above, if the probability is zero, the price of this contract is positive; while if the probability is large enough, the probability of a gain is significant enough, and $z$ is small enough, then the price of this contract is negative. We shall limit ourselves to the case where the probability of a forced realization is sufficiently small that the price of this contract is positive.

There is a discontinuity in $\hat{p}$ at $t=1$. Once the asset has become long-term, the price paid for realization is much reduced; and given our stationarity assumptions, after $t=1$ both the benefits and costs remain unchanged.

Finally, we note the effect of the differential taxes on long-term and shortterm gains on $\hat{p}$. If long-term and short-term gains are taxed at the same rate,

$$
\hat{p}=1 \text { for all } t
$$

For, assume $\hat{p}(t)>1$. We argued that the only reason that there is an advantage to realizing a gain was that it put us in a position to realize a short-term loss. Assume that subsequently at $\tilde{t}$ we realized a loss of $\hat{p}-\tilde{p}$. If we had simply waited until $\tilde{p}$, the PDV of our tax liabilities would have been $\tau(\tilde{p}-1) \mathrm{e}^{-r \tilde{z}}$ rather than $\tau\left[(\hat{p}-1) \mathrm{e}^{-r t}+(\tilde{p}-\hat{p}) \mathrm{e}^{-r \tilde{t}}\right]$. Conversely, if $\hat{p}(t)<1$.

Consider now the other limiting case, where $z=0$, i.e. there is no long-term capital gains tax. Then, just after $t-1$ the individual would realize his gain; there is no cost to obtaining the 'put' and (under our assumptions, if the rate of forced realizations is low enough) considerable benefit. It immediately follows that, once again, $\hat{p}(t)=1^{24}$ for $0 \leqq t \leqq 1$.

We can summarize this discussion in:

Proposition 7. There is a critical $\hat{p}(t)$ such that if $p(t)<\hat{p}(t)$, the individual sells his asset. $\hat{p}$ satisfies the following properties:

(a) $\hat{p}(0)=1$;

(b) $\quad \hat{p}(t) \geqq 0 \quad$ for $t>1$;

(c) $\quad \lim _{t \rightarrow 1} \hat{p}(t) \leqq \lim \hat{p}(t) \geqq 1$,

\footnotetext{
${ }^{24}$ Assume $\hat{p}(f)>1$, for some $\hat{f}, 0<\hat{t}<1$. As before, the only reason to sell is to take advantage of the provisions for tax losses, in the interval $(\hat{t}, \hat{t}+1)$. Our earlier argument established that if the date of subsequent realization was within the period $(0,1)$, no advantage was served by the earlier realization. On the other hand, if the realization was in the interval $(1,1+f)$, again no advantage is served, since at worst the individual would have, at 1 , realized his long-term capital gain without paying any taxes. Similar arguments show that $\hat{p}$ cannot be less than 1 .
} 


$$
\begin{aligned}
& \lim _{z \rightarrow 0} \hat{p}(t)=\lim _{z \rightarrow 1} \hat{p}(t)=1 \quad \text { for } 0 \leqq t \leqq 1 \\
& \lim _{z \rightarrow 0} \hat{p}(t)=\infty \quad \text { for } t>1 \\
& \lim _{z \rightarrow 1} \hat{p}(t)=1 \quad \text { for } t>1 \\
& \frac{\mathrm{d} \hat{p}}{\mathrm{~d} z}<0 \quad \text { for } t>1
\end{aligned}
$$

Although in this and the preceding section we have analyzed the optimal investment strategy of an investor under rather particular assumptions, elsewhere we have explored alternative formulations. The result that, provided the capital gain is not too large, it is desirable to realize gains as soon as they become eligible for long-term treatment, appears to be robust. $^{25-27}$

\section{PART III: The welfare analysis of capital gains taxation}

\section{Exchange efficiency, production efficiency, and the locked-in effect}

There has been considerable concern over the distortionary effects of capital gains taxation, especially over the locked-in effect. The analysis of the preceding sections has raised two important points: in a perfect capital

\footnotetext{
${ }^{25}$ The analysis of this and the preceding section assumed that the binding constraint imposed on the individual is his ability to borrow. He would like to take a greater position in the risky asset, but cannot. In Stiglitz (1981b) we consider another polar case: the individual keeps his level of holdings of the risky asset fixed. As he realizes his losses, the tax rebates are added to consumption; when he realizes a gain, he pays for the taxes by reducing consumption. We calculate the expected present discounted value of tax liabilities associated with alternative portfolio strategies, and show, once again, that the policy of realizing gains as soon as they become eligible for long-term treatment may be the preferable policy.

${ }^{26}$ In Stiglitz (1981b) we also consider a discrete time, dynamic programming formulation. Note that a risk-averse individual is more likely to take the policy of realizing capital gains as soon as they become eligible for long-term treatment than a risk-neutral individual; for such a policy yields a positive 'tax' return to the individual in precisely those states of nature when the value of the security has decreased. Thus, this strategy provides a kind of insurance against losses.

${ }^{27}$ In our analysis we have ignored transactions costs. For wealthy individuals, transactions costs are not significant, relative to the possible gains to be had. For instance, with the present tax law, with long-term gains being taxed at 40 percent of short-term gains, a security with a two-point distribution $\{g,-l\}$ with equal probabilities generates an expected tax cash flow of $\frac{1}{2} \tau(l-0.4 g)$ if the individual pursues the policy of always realizing gains. Hence, if $g>l>0.4 g$ it is clear that this cash flow can be positive while the expected return to the asset is also positive. For high variance securities, this cash flow can exceed any reasonable estimate of transaction costs.
} 
market, there are no real consequences of capital gains taxation; while in an imperfect capital market, there may or may not be a locked-in effect. The fact that distortionary effects only occur in markets with some capital market imperfection makes any welfare analysis tenuous: we cannot rely on the fundamental theorem of welfare cconomies to say that in the absence of taxation, the market equilibrium would have been Pareto optimal [see Stiglitz (1981c)]. What is required is a second-best analysis, which would take us beyond the scope of this paper. We can, however, attempt to identify the kinds of distortions introduced by the capital gains tax, in particular, those arising from the locked-in effect, when it occurs. The locked in effect has two consequences.

(a) The economy will no longer have the property of 'exchange' efficiency. There are transfers of ownership of assets which could make both parties to the transfer better off, which, because of the tax, will not take place. There is some question, however, concerning the magnitude of the associated welfare loss. In particular, the importance that one ascribes to the locked-in effect on the stock market depends on one's view of the role of the stock market in allocating real resources (as opposed to providing a convenient gambling casino for wealthy individuals). [See Stiglitz (1982a).]

(b) The capital gains tax interferes with the 'productive' efficiency of the economy. There are at least three ways that capital gains taxation may interfere with the productive efficiency of the economy. First, there is a widespread belief that the locked-in effect gives rise to greater volatility of asset prices, and this greater price volatility makes investments in equities less attractive. Secondly, in those situations where ownership of assets affects the uses to which they are put, the impediments to the transfer of ownership of assets to those who can best manage them may result in significant productive losses to the economy. ${ }^{28}$ Thirdly, when the return to an investment project is realized in the form of a capital gain, then the date of termination of the project affects the present value of the tax liability, and hence the project may be terminated at a date different from when it would have otherwise have been terminated.

In the following sections we construct simple models examining some aspects of these distortions associated with capital gains taxation.

\section{The locked-in effect and price instability}

In the preceding section we noted that there was a widespread belief that because the locked-in effect results in thinner markets, prices are likely to be more volatile. To assess this allegation, one needs to construct a general

\footnotetext{
${ }^{28}$ The importance of the relationship between ownership and control has long been recognized; see, for example, Knight (1921). It has been stressed in the more recent literature on principal-agent relationships.
} 
equilibrium model. It is not, for instance, obvious that thinner markets result in greater price volatility; the locked-in effect might reduce the supply of assets and the demand for it proportionately (owners of firm A are 'locked in' and so do not offer it for sale; but owners of other firms are also 'locked in' and so do not offer to buy). ${ }^{29}$

The present section provides the simplest dynamic general equilibrium model, which shows that the capital gains tax may indeed result in greater price volatility. ${ }^{30}$ We also show that it may result in exchanges not occurring which otherwise would have occurred (but it may not necessarily do so).

There are two groups in the population, two states of nature, one risky security to be traded, and no short sales. In state 0 , the dividend is $\alpha$; in state 1 it is $\beta$. We let $\alpha_{i}$ and $\beta_{i}$ denote the after-tax dividends received by group $i$. When the economy is in state 0 the probability that it will be in state 0 next period in the judgement of individuals of type $i$ is $\pi_{00}^{i}$; similarly, when it is in state 1 , the probability that it will be in state 1 next period is $\pi_{11}^{i}$. The two groups may differ in their judgments about the transition probabilities (equivalently, since what we will be interested in is the marginal utility of income in each state times the probability, that product will differ between the two groups even when, with rational expectations, they agree on the transition probabilities).

In each state, the security will be held by the group which values it most highly. The valuation of the security depends, of course, on what they believe they can sell the security for, if they desired to sell it. For simplicity, we shall focus on the case where group A holds the security in state 0 , group B holds the security in state $1 .^{31}$ Then:

$$
\begin{aligned}
& V_{0}=\delta\left[\pi_{\mathrm{A}}\left[\alpha_{\mathrm{A}}+V_{0}\right]+\left(1-\pi_{\mathrm{A}}\right)\left[\beta_{\mathrm{A}}+V_{1}-z \tau_{\mathrm{A}}\left(V_{1}-V_{0}\right)\right]\right] \\
& V_{1}=\delta\left[\pi_{\mathrm{B}}\left[\alpha_{\mathrm{B}}+V_{0}-z \tau_{\mathrm{B}}\left(V_{0}-V_{1}\right)\right]+\left(1-\pi_{\mathrm{B}}\right)\left[\beta_{\mathrm{B}}+V_{1}\right]\right]
\end{aligned}
$$

\footnotetext{
${ }^{29}$ These arguments implicitly assume a kind of imperfection in the capital market; gambles on the price of a security are not restricted to the number of shares outstanding; and individuals' demands for securities need not be restricted by their reluctance to sell their present holdings, if they can borrow against these or sell these (or equivalent) securities short.

${ }^{30} \mathrm{We}$ suspect that the likelihood that the capital gains tax leads to greater price volatility is even greater than our simplified model suggests. Assume, for instance, that there are two groups in the population, one of which has volatile beliefs about the return on the risky security, the other of which has very stable beliefs. In the absence of capital gains taxation, the stable group sells to the volatile group when the latter is optimistic, dampening out the price fluctuations from what they would be if only members of the volatile group traded with each other. The locked-in effect may remove the stable group from the market (particularly in intlationary periods); since those who are very optimistic about the return in some security are willing to sell their present assets, and pay a capital gains tax, to buy the security about which they have become optimistic, the members of the more volatile group will not be locked in to the same extent that members of the stable group are. With only the more volatile individuals remaining in the market, the price variability will more fully reflect the volatility of their expectations.

${ }^{31}$ The restrictions on the parameters which must be satisfied for this to be a consistent solution are set forth in Stiglitz (1981b).
} 
where

$V_{i}=$ value of security in state $i$,

$\delta=$ discount factor,

$z$ = ratio of capital gains tax to tax on ordinary income,

$\tau_{i}=\operatorname{tax}$ on ordinary income of group $i$,

$\pi_{\mathrm{A}}=\pi_{00}^{\mathrm{A}}, 1-\pi_{\mathrm{B}} \equiv \pi_{11}^{\mathrm{B}}$.

Solving (1) and (2) simultaneously, we obtain:

$$
\begin{gathered}
V_{0}=\frac{\delta d_{\mathrm{A}}+\frac{\delta\left(1-m_{\mathrm{A}}\right) \delta d_{\mathrm{B}}}{1-\delta\left(1-m_{\mathrm{B}}\right)}}{1-\delta m_{\mathrm{A}}} / 1-\frac{\delta\left(1-m_{\mathrm{A}}\right)}{1-\delta m_{\mathrm{A}}} \frac{\delta m_{\mathrm{B}}}{1-\delta\left(1-m_{\mathrm{B}}\right)}, \\
V_{1}=\frac{\delta d_{\mathrm{B}}+\frac{\delta m_{\mathrm{B}}}{1-\delta m_{\mathrm{A}}} \delta d_{\mathrm{A}}}{1-\delta\left(1-m_{\mathrm{B}}\right)} / 1-\delta\left(\frac{m_{\mathrm{B}}}{\left(1-\delta\left(1-m_{\mathrm{B}}\right)\right.}\right)\left(\frac{1-m_{\mathrm{A}}}{1-\delta m_{\mathrm{A}}}\right) \delta .
\end{gathered}
$$

where

$$
\begin{aligned}
& d_{i}=\alpha_{i} \pi_{i}+\left(1-\pi_{i}\right) \beta_{i}, \\
& m_{\mathrm{A}}=\pi_{\mathrm{A}}+z \tau_{\mathrm{A}}\left(1-\pi_{\mathrm{A}}\right), \\
& m_{\mathrm{B}}=\pi_{\mathrm{B}}\left(1-z \tau_{\mathrm{B}}\right) .
\end{aligned}
$$

We are interested in the effect of taxation on price volatility. Hence, we calculate

$$
\begin{aligned}
\frac{V_{0}}{V_{1}} & =\frac{d_{\mathrm{A}}+\delta\left[m_{\mathrm{B}} d_{\mathrm{A}}-m_{\mathrm{A}} d_{\mathrm{B}}\right]+\delta\left[d_{\mathrm{B}}-d_{\mathrm{A}}\right]}{d_{\mathrm{B}}+\delta\left[m_{\mathrm{B}} d_{\mathrm{A}}-m_{\mathrm{A}} d_{\mathrm{B}}\right]} \\
& -1+\frac{\left(d_{\mathrm{A}}-d_{\mathrm{B}}\right)(1-\delta)}{d_{\mathrm{B}}+\delta\left[m_{\mathrm{B}} d_{\mathrm{A}}-m_{\mathrm{A}} d_{\mathrm{B}}\right]}
\end{aligned}
$$

From this we can easily calculate the effect of any change of taxation on price volatility. We examine one special case, leaving other cases to the reader. We assume that the probability of a transition from state 0 to 1 is equal to the probability of a transition from state 1 to state 0 , in the judgment of the individual holding the security (which differs in the two states). We assume moreover that $\tau_{\mathrm{A}}=\tau_{\mathrm{B}}$. Hence:

$$
\frac{V_{0}}{V_{1}}=1+\frac{(\alpha-\beta)(1-\delta)\left(\pi_{\mathrm{A}}-\pi_{\mathrm{B}}\right)}{\left(\alpha \pi_{\mathrm{B}}+\left(1-\pi_{\mathrm{B}}\right) \beta+\delta\left\lceil\beta\left(\pi_{\beta}-\pi_{\mathrm{A}}\right)-z \tau\left(1-\pi_{\mathrm{A}}\right) \beta+\alpha \pi_{\mathrm{BTG}}\right]\right)},
$$




$$
\frac{\mathrm{d} V_{0} / V_{1}}{\mathrm{~d} z \tau} \sim(\alpha-\beta)\left(\pi_{\mathrm{A}}-\pi_{\mathrm{B}}\right)
$$

From (4) $V_{0} / V_{1} \gtrless 1$ as $(\alpha-\beta)\left(\pi_{\mathrm{A}}-\pi_{\mathrm{B}}\right) \gtrless 0$; hence, an increase in the capital gains tax increases volatility.

We can also use this model to show that the capital gains tax may result in exchanges which would have taken place in the absence of capital gains taxation not occurring. To see this, we recall that for (1) and (2) to describe the equilibrium, the valuation of the risky security in state 0 must be higher for group A than for group B. Assume individual B initially owns the shares. We can calculate how much he receives, after paying capital gains tax, if he sells. (What A will be willing to pay depends, as we have already noted, on how much tax A will have to pay when, subsequently, he resells back to B.) Similarly, we can calculate how much it is worth to B to retain the asset permanently. If the capital gains tax rate is high enough, the latter is greater than the former and no transaction occurs.

There is, as we have noted, some debate about the welfare significance of the reduced trading and increased price volatility in the stock market. If the stock market is nothing more than a rich man's gambling casino, then perhaps one should not bo too concerned. On the other hand, if ownership and control are linked, the locked-in effect may result in the asset being owned - and thus controlled - by an individual, when some other individual would be able to put the asset to better use.

\section{Real investments and capital gains taxation}

In this section we focus on the real effects of capital gains taxation: ${ }^{32}$ the impact it has on the kinds of investment projects undertaken. To do this, we employ the standard Austrian capital model; in Stiglitz (1981a) I showed that (i) there was some tendency for projects to be terminated too early, not too late; and (ii) if one could not infer unambiguously from observed average returns what the marginal returns were, then there was no method of constructive realization which was non-distortionary.

Here, I wish both to generalize and to qualify this first result: to show that there is a general class of problems for which the techniques employed there can be used to show that the first result is valid, but, at the same time, that there are other important classes of problems for which the 'conventional' wisdom, that projects will be terminated too late, is true.

We assume an investment of a dollar yields, after a period of $T$ years, a return of $f(T)$. The question posed is: At what date (or for what size 'tree')

\footnotetext{
${ }^{32}$ See also Stiglitz (1973) and Dasgupta, Heal and Stiglitz (1980). In the latter we explore the effects of capital gains taxation on a particular class of productive assets - exhaustible natural resources.
} 
should the project be terminated? While in the portfolio models considered in earlier sections, we assumed the (expected) percentage return was constant over time (although this was not essential for some of the results), here we assume that there is diminishing returns.

The impact of taxation will be shown to depend on two critical factors: (1) whether the project is treated in isolation, or is one of a sequence of related projects; e.g. whether when the tree is cut down it will be replaced by another tree; and (2) the extent to which the rate of discount (after tax) is affected by the capital gains tax (i.e. the extent to which there is effective shifting of the capital gains tax).

\subsection{Isolated projects}

The individual seeks to

$$
\max [f(T)(1-\tau)+\tau] \mathrm{e}^{-\hat{r} T}-1,
$$

where, as before, $\tau=\operatorname{tax}$ rate and $\hat{r}=$ after-tax rate of interest. The solution to this is

$$
f^{\prime}=\hat{r}\left[f+\frac{\tau}{1-\tau}\right]
$$

There are two effects: $\hat{r}$, the after-tax rate of interest, may well be below its before tax rate. This leads to $T$ being larger than without taxation. On the other hand, clearly

$$
f+\frac{\tau}{1-\tau}>f
$$

and this leads to $T$ being smaller than it othetwise would be. If there is no change in the before-tax real ratc of intercst, so

$$
\hat{r}=r(1-\tau)
$$

then $T$ is greater than it would be without taxation. On the other hand, if there is no change in the after-tax real rate of interest, $T$ is smaller than it otherwise would be (a negative locked-in effect).

\subsection{Replacement}

Assume now that there is a fixed piece of land, on which a single tree could grow. Again, we ask: What is the optimal size at which to terminate 
the project (cut the tree down)? We let $V$ be the optimal value of the sequence of investment projects; because of the time invariance assumption, we can write

$$
V=\mathrm{e}^{-\hat{\boldsymbol{r}} T}[f(T)(1-\tau)+\tau-1+V]
$$

so

$$
V=\frac{\mathrm{e}^{-\hat{r} T}[(f(T)-1)(1-\tau)]}{1-\mathrm{e}^{-\hat{\boldsymbol{r} T}}} .
$$

It is immediate that $\tau$ only affects the optimal value of $T$ through its effect on $\hat{r}$. Straightforward differentiation shows that so long as an increase in the tax rate reduces the after-tax return, an increase in the tax will result in an increase in the cutting size, i.e. trees will be cut down later than they otherwise would be.

\subsection{Stochastic growth}

Following our earlier analysis [Stiglitz (1981a)] and using the techniques employed in Brock, Rothschild and Stiglitz (1982), we can easily extend this analysis to the case of trees with uncertain growth. Under quite general conditions, it can be shown that if the stochastic process describing growth is stationary, the optimal policy can be expressed in terms of an optimal cutting size (termination size for the project, $X^{*}$ ). The expected present discounted value of the project is thus

$$
E \mathrm{e}^{-\tilde{r} T}[X(1-\tau)+\tau]-1,
$$

where $T$ is the first time the tree reaches size $X$. Let $H(T, X)$ be the distribution of the first passage time to the size $X$, and let $M(X, r)$ be the moment-generating function of the first passage time:

$$
M(X, r)=\int_{0}^{\infty} \mathrm{e}^{-r T} \mathrm{~d} H(T, X)
$$

Then our maximization problem can be reformulated as:

$$
\max M(X, \hat{r})[X(1-\tau)+\tau]-1
$$

The optimal value of $X$ satisfies

$$
\frac{M_{X}}{M}[X(1-\tau)+\tau]+(1-\tau)=0,
$$


so

$$
\frac{\mathrm{d} X}{\mathrm{~d} \tau} \sim M_{X}(1-X)-M+\frac{\mathrm{d} \hat{r}}{\mathrm{~d} \tau}\left\{[X(1-\tau)+\tau] M_{X r}+(1-\tau) M_{r}\right\}
$$

If $r$ remains unchanged, the tax always reduces the cutting size (as in the non-stochastic case), but the magnitude of the change, as wcll as the direction, in the case where $r$ changes, will depend on the nature of the stochastic process.

Finally the same arguments show that with replacement, the firm's maximization problem is

$$
\max \frac{X M(1-\tau)}{1-M}-1
$$

where the only effect of $\tau$ on $X$ is through its effect on $\hat{r}$, just as in the nonstochastic case.

\subsection{Other provisions}

The analysis of the preceding subsection ignored the impact of a large number of provisions of the tax code, which can significantly affect the outcome. For instance, if there is a step up of the basis at death, then an individual expecting to die in the near future may postpone the realization of a capital gain (cutting down the tree), even when the real rate of return is much less than the rate of interest [or even $r(1-\tau)]$. Similarly, for many assets the choice of durability is affected not only by the capital gains tax, but equally importantly by the relationship between the true economic rate of depreciation and the maximum allowable depreciation rate.

\subsection{Production and exchange}

Our earlier analysis should make it evident that, in the case where there is no differential treatment between (short-term) gains and (long-term) losses and when all individuals are in the same tax bracket, it never pays to exchange an asset on which there is a capital gain prior to the termination of the project (again assuming a perfect capital market). By the same token, when growth is stochastic, it always pays to exchange an asset when its 'size' is smaller than at the time of purchase. ${ }^{33}$

\footnotetext{
${ }^{33}$ This plays an important role in oil leasing. When exploration reveals that there is (in an expected value sense) less oil than had originally been thought, there is a decrease in the value of the lease. In some cases, it may be profitable simply to terminate the project, to obtain the tax write-off, even though in the absence of taxation the project might be continued.
} 
When, however, there are individuals at different tax brackets, then there will be transfers of ownership prior to the project termination. For instance, assume there is some tax-exempt individual, and the solution to (5), $\hat{T}$ (the date of termination of the project for the taxed individual) is less than $T^{*}$, the solution

$$
f^{\prime}\left(T^{*}\right)=r f\left(T^{*}\right)
$$

(the termination date withoul laxes). Then the value of this tree at $\hat{T}$ is not $f(\hat{T})$, but $f\left(T^{*}\right) \mathrm{e}^{-r\left(T^{*}-\hat{T}\right)}>f(\hat{T})$.

We commented in our discussion above that there may be an important link between production and exchange, when ownership and control are linked together, and when there are significant differences in different individuals' ability to manage particular assets. It should be noted that what we have referred to as the termination of a project does not necessarily correspond to 'chopping down a tree'. It may, instead, represent a transfer of management of the tree. The tree with a new manager is a different project (in our terminology) than the tree with the old manager. The social loss then in a delay in the termination of a project is simply the difference between what the growth would have been, under the new management, and what it was under the old; similarly, for an early termination of a project. ${ }^{34}$

Not all realizations result in a change in control; an investor may be induced by tax considerations to sell some shares at a different date than he otherwise would, but so long as the number of shares is small, there need not be a change in the management (and hence in the productive uses to which the assets are put). In that case, the only inefficiency arising out of the capital gains tax is an exchange inefficiency. If the assets which would have otherwise been exchanged but are not, are not too dissimilar, the consumer surplus lost as a result of this exchange inefficiency may be relatively small, even though the amount of trade impeded in the market may be very large. ${ }^{35}$

\section{PART IV}

\section{Macro-economic effects}

\subsection{Revenue effects}

We showed in our analysis above that there was some possibility that a

\footnotetext{
${ }^{34}$ Similar inefficiencies arise in the estate tax, in the presence of an imperfect capital market. Estates with large tax liabilities often must sell ongoing establishments to raise the capital to pay the tax. Note that if capital markets were perfect, and if the existing management in fact represented the best use of the resources, then the individuals could borrow to pay the estate duty.

${ }^{35}$ The impediment to the sale of shares which results in the original owner owning more shares than he otherwise would may, in addition, lead the firm to undertake less risk than it otherwise would.
} 
lowering of the tax rate on long-term capital gains would lead to increased realization of long-term gains. In the very short run, this would increase government revenue; in the long run, however, it is likely to decrease government revenue for three reasons.

(1) The individual is choosing to pay a tax today which he would have had to pay at some date in the future. The increase in tax revenue is largely simply a change in timing.

(2) If, as we have argued, one of the motivations for the realization of long-term gains is for the individual to be in a position to take advantage of the ability to write off short-term losses at full rates, then there will be, as a result, a negative cash flow from the treasury. ${ }^{36}$

(3) The short-run increase in government revenues is partly the effect of moving from one steady state to another. Within the new steady state, there are three effects that have to be reckoned with: (i) given that the economy is growing, a shorter holding period will be associated with more recent investments, and therefore with a larger base; (ii) on the other hand, the fact that the investments are terminated earlier means that each will have experienced a smaller level of capital gains; and (iii) since a lower tax rate is imposed, the tax revenues generated will be even smaller.

To see this heuristically, assume the average tax rate on realizations, when the ratio of the tax rate on long-term capital gains to that on ordinary income is $z$, is $\tau(z)$, with $\tau^{\prime}>0$; when $z$ is lowered, $\tau$ is lowered, both because of the direct effect of the lower $z$, and the indirect effect of the greater opportunity to take advantage of losses. Thus $\tau^{\prime} z / \tau \geqq 1$. Assume that investments are growing at the rate $g$, and the average capital gain on investments (per dollar invested) realized after $T$ years is $f(T)-1$. Thus, the steady state flow of tax revenue is proportional to

$$
\tau \mathrm{e}^{-g T}(f(T)-1) \text {. }
$$

Differentiating logarithmically with respect to $z$, we obtain:

$$
\frac{\tau^{\prime} z}{\tau}-\left[g-\frac{f^{\prime}}{f-1}\right] \frac{\mathrm{d} T}{\mathrm{~d} z}=\frac{\tau z^{\prime}}{\tau}-\left[g+\frac{\hat{r}}{1-\tau}\left(\tau-\frac{f}{f-1}\right)\right] \frac{\mathrm{d} T}{\mathrm{~d} z} .
$$

If, now, we assume that the interest rate is not less than the rate of growth, and if lowering the tax rate lowers the holding period, the steady state flow of tax revenues is reduced, at least for values of $\tau$ near zero. ${ }^{37}$

\footnotetext{
${ }^{36}$ This negative cash flow will not, however, be reflected in the returns recorded on schedule D because of the restrictions on the deductibility of losses; it will, however, be reflected in the deductions for interest payments and losses on ordinary income.

${ }^{37}$ Even if the after-tax rate of interest is less than the rate of growth (as, for instance, Gordon has recently argued) the steady state effect may well be negative.
} 
This long-run effect is markedly different from the short-run effect. In the transition from one steady state, with say $T=T_{1}$, to another steady state with $T=T_{2}$ (where $T$ is the average holding period), all those assets invested in the interval between $t-T_{1}$ and $t-T_{2}$ are sold [where $t$ is the date of the (unanticipated) tax change], i.e. there is a one time sale proportional to

$$
\frac{\mathrm{e}^{g T_{1}}-\mathrm{e}^{g T_{2}}}{g}
$$

Clearly, if the transition sales occur rapidly enough, there will be a shortterm increase in tax revenues accompanied by a long-run decrease in tax revenues. Offsetting these effects there are positive effects from any increased efficiency in the economy (resulting from the reduction in a distortion) and from any increased savings. ${ }^{38}$

There is, however, no reason to believe that the government should take either the extremely short-sighted view of looking at current tax revenues, or the extreme long-run view of looking only at steady state revenues. Indeed, in other contexts we have learned that focusing on steady states, ignoring transitions, may be extremely misleading.

A more reasonable view for the government to take is to ask: What is the effect of the change in the long-term capital gains tax rate on (a) the present discounted value of tax revenues; (b) the current level of consumption; and (c) the level of private savings and the pattern of its allocation?

It is clearly possible that (even apart from the direct effect of the lowering of the tax rate) the change in timing may reduce the present discounted value of tax revenues. To see this most simply, we return to a modified version of the two-period model of section 4 , where an individual has experienced a capital gain of $p_{1}-1$. The tax rate on capital gains this period is $z_{1} \tau$ and next period it is expected to be $z_{2} \tau, z_{2}>z_{1}$. Consider the individual who is indifferent between terminating the project and reinvesting the proceeds in a

\footnotetext{
${ }^{38}$ In the discussion so far, we have assumed that the realization of an asset corresponded to its termination (the chopping down of a tree). Similar results obtain, however, if a realization simply represents a change in ownership. For simplicity, let us assume that all assets grow at the market rate of interest $r$, and all realizations occur after $T$ periods of ownership. At any date, then, there are $\mathrm{e}^{-\boldsymbol{g} T}$ units of assets which are invested $T$ years ago being realized, each of which now has increased in size by an amount $\mathrm{e}^{r T}-1$. Similarly, there are $\mathrm{e}^{-2 g T}$ units of assets which were invested $2 T$ years ago being realized, each of which now has increased in size to $\mathrm{e}^{2 r T}$, etc. The total capital gains tax liability is proportional to (provided $g>r$ )

$$
\left(\mathrm{e}^{r T}-1\right)\left\{\mathrm{e}^{-g T}+\mathrm{e}^{-2 g T} \mathrm{e}^{r T}+\mathrm{e}^{-3 g T} \mathrm{e}^{2 r T} \ldots\right\}=\left(\mathrm{e}^{r T}-1\right) \frac{\mathrm{e}^{-g T}}{1-\mathrm{e}^{(r-g) T}} .
$$

For $r$ near $g$, the derivative of this with respect to $T$ is positive: reducing the holding period will reduce the steady state flow of government revenues. On the other hand, for $g \gg r$ the derivative of this with respect to $T$ is negative: reducing the holding period will increase the steady flow of revenues.
} 
one-period project which will yield a rate of return of $g_{2}$, so his after-tax terminal wealth is (where $T_{1}$ is his tax payment the first period, $T_{2}$ the second)

$$
\left[\left(p_{1}-1\right)\left(1-z_{1} \tau\right)+1\right]\left(1+g_{2}\left(1-z_{2} \tau\right)\right)=\left(p_{1}-T_{1}\left(1+g_{2}\right)-T_{2},\right.
$$

and keeping his funds in the current project, which will, over the next period, increase in value at a rate $g_{1}$, so his after-tax terminal wealth is

$$
p_{1}\left(1+g_{1}\right)\left(1-z_{2} \tau\right)+z_{2} \tau=p_{1}\left(1+g_{1}\right)-\hat{T}_{2},
$$

where $\widehat{T}_{2}$ is his tax payment. In the first case, the government's present discounted value of revenue is

$$
z_{1} \tau\left[p_{1}-1+\frac{g_{2}}{1+r}\left(\left(p_{1}-1\right)\left(1-z_{2} \tau\right)+1\right)\right]=T_{1}+\frac{T_{2}}{1+r}
$$

while in the second it is

$$
\frac{z_{2} \tau\left[p_{1}\left(1+g_{1}\right)-1\right]}{1+r}=\frac{\hat{T}_{2}}{1+r}
$$

Equating (6) and (7), and simplifying, we obtain that the difference in the government revenues is

$$
\frac{z_{1} \tau\left(p_{1}-1\right)\left(r-g_{2}\right)+p_{1}\left(g_{2}-g_{1}\right)}{1+r} .
$$

Hence, provided that the government's discount rate is not too large, and provided the efficiency gains $\left(g_{2}-g_{1}\right)$ are not too large, the earlier realization reduces the present discounted value of government revenue.

If individuals' discount rates are higher than the government's, and if the present discounted value of tax payments, using the individual's discount rate, is the same for an investment program involving shorter holding period as it is for an investment program involving longer holding periods, then the present discounted value of the government's revenue, using the lower, government discount rate, is higher with the longer holding period, provided the efficiency loss is not too great.

\subsection{Effects on savings}

All of the analysis so far has assumed that when the individual realizes his capital gain, he will reinvest his after-tax proceeds in a productive investment, and will not use the proceeds to increase his consumption.

Even if consumption is unaffected, the earlier realization will lead to a reduction in the level of private savings, by an amount equal to the tax 
payment to the government. The usual argument that the ability of individuals to postpone their taxes by postponing realization is equivalent to a loan from the government, can be looked at in just the opposite way: it is a loan specifically directed at productive opportunities within the economy (although the critical rate of return on the investment may be below the market rate of interest). The increase in government tax revenues can, in this view, be thought of as coming directly out of private savings, rather than out of consumption.

This is, of course, only a first-order approximation. We now need to enquire whether a lowering of the tax on long-term capital gains, and the shortening of the holding period that might result, will lead to an increase in consumption, thus further reducing the private savings available for investment, or to a decrease in consumption. Not surprisingly, either result is possible under not implausible conditions.

First, consider an individual who is almost indifferent between the two strategies, of selling capital gains as soon as they become long-term, and realizing only losses; we can view a switch from the second strategy to the first as a mean utility-preserving reduction in the (after-tax) riskiness of the investment. Such a change can be shown to leave consumption unaffected if relative risk aversion is constant and if all income comes from the risky asset; if relative risk aversion is decreasing, then consumption will increase. On the other hand, if the income from the risky asset is only a fraction of the individual's total income, then even with constant relative risk aversion there will be some reduction in consumption.

If individuals are constrained in their borrowing, there may also be a liquidity effect leading individuals to increase their consumption upon the sale of their assets [see Stiglitz (1981a)].

There is a third effect. If individuals are risk averse, they will not, in general, pursue one policy to the exclusion of the other; changing $z$ will affect the proportion of one's capital gains that are realized. Moreover, individuals will alter the proportions in which they invest in risky assets versus safe assets. $^{39}$

The important conclusion of this section is that changes in capital gains tax rates and tax revenues have markedly different effects from those from other forms of taxes. The short-run impact is primarily a transitional effect, representing the change from one steady state level of holding periods to another. This has little to do with the long-run effects, which may well be of the opposite sign. More important, whether tax revenues increase or decrease, the income effect of a lowering of the tax rate on capital gains is

\footnotetext{
${ }^{39}$ Again, a slight reduction in $z$, which induces a change to a shorter mean holding period, can be thought of as inducing a mean utility-preserving reduction in the riskiness of the risky security. It is known that if there is decreasing absolute risk aversion and increasing relative risk aversion, this will lead to a decrease in the value of holdings of the safe asset.
} 
always positive, leading to an increase in consumption. As usual, the substitution effect may offset this. But in addition to these two standard effects, we have noted the possible existence of a third - the liquidity effect - which, to the extent that holding periods are shortened, may increase consumption; and of a fourth effect, the risk effect, which may lead to an increase or decrease in consumption depending on the individual's utility function and the share of income arising from returns on the risky asset.

Equally important, we have argued that to the first order of approximation, changes in capital gains tax revenues can be thought of as coming directly out of funds available for private investment, rather than out of consumption. Just as social security represents an asset, the anticipation of which depresses private savings and investment, the existence of the deferred tax liabilities associated with longer holding periods represents a liability, which increases private savings and investment.

Within this perspective, it is difficult to know what significance should be attached to the admittedly controversial empirical studies of Feldstein et al., 1980 , that lowering the tax on long-term capital gains will increase (in the short run) government tax revenue.

\section{Conclusions}

This paper has shown that the analysis of the effects of capital gains taxation requires a careful modelling both of the details of the tax code and the imperfections in the capital market. Under the standard assumptions concerning perfect capital markets and under the standard idealizations of the tax code, there are several strategies by which rational investors can avoid not only all taxes on their capital income, but also all taxes on their wage income; these strategies leave individuals' consumption and bequests in each state of nature and at each date unchanged from what they would have been in the absence of taxes. Although certain detailed provisions of the tax code may limit the extent to which rational investors can avail themselves of these tax-avoidance activities, there are ways, in a perfect capital market, by which the effects of these restrictions can be ameliorated. We have contended, accordingly, that any analysis of the effects of capital taxation must focus on imperfect capital markets.

If individuals face limitations on the amounts which they can borrow and/or if there are limitations on short sales, then we have shown that there are circumstances where there is a locked-in effect; but there are other circumstances where individuals are induced to sell securities that they otherwise would have held, in order to take advantage of the asymmetric treatment of short-term losses and long-term gains. $\Lambda$ policy of realizing gains as soon as they become eligible for long-term treatment (provided the gains are not too large) dominates the policy of postponing the realization of capital gains. 
While we have constructed a simple general equilibrium model, within which we can confirm the widespread belief that the taxation of capital gains may increase the volatility of asset prices, and lead individuals not to trade when they otherwise would, we have cast some doubt on the significance of the welfare losses resulting from these exchange inefficiencies. At the same time, we have seen that there are circumstances in which the tax leads to production inefficiencies, e.g. terminating projects at other than the socially optimal date.

Finally, we have argued that the focus of some recent policy debates on the short-run revenue impact of a decrease in the tax rate on capital gains is misplaced: even when the short-run revenue impact is positive, consumption may increase (thus exacerbating inflationary pressures) and private savings may decrease (thus leading to a lower level of investment in the private sector). Moreover, we have argued that there is some presumption that the long-run revenue impact is negative.

Although our analysis has focused on the central theoretical issues involved in capital gains taxation, it has some important implications for empirical research. In particular, our analysis suggests that the impact of the tax is not adequately summarized by a single number, such as the 'effective tax rate' representing the average ratio of tax payments to capital gains. Moreover, the impact of the tax cannot be assessed by looking only at reported capital gains and losses.

Our analysis also has important policy implications for the reform of capital gains taxation, but a discussion of these must await another occasion.

\section{References}

Allen, F., 1982, On the importance of interaction of tax code provisions, University of Pennsylvania, mimeo.

Atkinson, A. and J.E. Stiglitz, 1980, Lectures on public economics (McGraw-Hill Co., New York and London).

Bailey, Martin J., 1969, Capital gains and income taxation, in: Arnold C. Harberger and M.J. Bailey, eds., The taxation of income from capital (The Brookings Institution, Washington, D.C.) $11-49$.

Brock, W., M. Rothschild and J.E. Stiglitz, 1982, Notes on stochastic capital theory, paper prepared at a Symposium on Insurance and Uncertainty in Economic Theory in honor of Karl Borch, Bergen, Norway.

Constantinides, G.M., 1980, Capital market equilibrium with personal tax, University of Chicago, mimeo.

Constantinides, G.M. and M.S. Scholes, 1981, Optimal liquidation of assets in the presence of personal tax: Implications for asset pricing, Journal of Finance, Papers and Proceedings.

Dasgupta, P., G. Heal and J.E. Stiglitz, 1980, The taxation of exhaustible resources, in: G.A. Hughes and G.M. Heal, eds., Public policy and the tax system (George Allen \& Inwin, London) 150-172.

David, M., 1968, Alternative approaches to capital gains taxation (The Brookings Institute, Washington, D.C.).

Feenberg, Dan, 1981, Dues the investment interest limitation explain the existence of dividends?, Financial Economics 99, 265-269. 
Feldstein, M., 1978, The appropriate taxation of capital gains: A response to John Yinger, Tax Notes, October.

Feldstein, M., J. Slemrod and S. Yitzhaki, 1980, The effects of taxation on the selling of corporate stock and the realization of capital gains, Quarterly Journal of Economics 94, 777791 .

Holt, C.C. and J.P. Shelton, 1962, The lock-in effect of the capital gains tax, National Tax Journal 15, 337-352.

Knight, F.N., 1921, Risk, uncertainty and profit (New York).

Minarik, J.J., 1981, Capital gains, in : H.J. Aaron and J.A. Pechman, eds., How taxes affect economic behavior (The Brookings Institution, Washington, D.C.) 241-277.

Stiglitz, J.E., 1973, Taxation, corporate financial policy, and the cost of capital, Journal of Public Economics 2, February, 1-34.

Stiglitz, J.E., 1981a, On the almost neutrality of inflation: Notes on taxation and the welfare costs of inflation, in: J. June Flanders and Assaf Razin, eds., Development in an inflationary world (Academic Press, New York and London) 420-260.

Stiglitz, J.E., 1981b, Modelling the effects of capital gains taxes on the accrual and realization of capital gains, report submitted to the Office of Tax Analysis, United States Treasury.

Stiglitz, J.E., 1981c, Pareto optimality and competition, Journal of Finance 36, 235-251.

Stiglitz, J.E., 1982a, Information and the capital market, in: William F. Sharpe and Cathryn Cootner, eds., Financial economics: Essays in honor of Paul Cootner (Prentice Hall, Englewood Cliffs, Ncw Jcrscy, 1982).

Stiglitz, J.E., 1982b, Ownership, control, and efficient markets: Some paradoxes in the theory of capital markets, in: M.K.P. Boyer and W.G. Sheperds, eds., Economic regulation: Essays in honor of James R. Nelson (Michigan State University Press, Ann Arbor). 